\title{
Processamento neural de frases em português brasileiro em monolíngues e bilíngues: um estudo com fMRI dos efeitos da compreensão leitora na ativação cerebral
}

Neural processing of Brazilian Portuguese sentences in monolinguals and bilinguals: an fMRI study of reading comprehension effects on brain activation

Cyntia Bailer

Universidade Regional de Blumenau - FURB - Blumenau - Santa Catarina - Brasil

\section{Lêda Maria Braga Tomitch}

Universidade Federal de Santa Catarina - UFSC - Florianópolis - Santa Catarina - Brasil

Resumo: Este artigo apresenta um recorte de uma tese desenvolvida no Núcleo de Estudos em Leitura ${ }^{1}$ na Universidade Federal de Santa Catarina em parceria com o Center for Cognitive Brain Imaging na Carnegie Mellon University (Pittsburgh, PA, EUA). O estudo, de natureza transversal, quantitativa e exploratória, objetivou investigar cérebros de monolíngues do português-brasileiro e bilíngues do par linguístico português-brasileiro e inglês e sua resposta neuroanatômica ao processamento de frases escritas. Para os fins deste artigo, delimitou-se detalhar os resultados relativos ao objetivo de investigar as áreas cerebrais recrutadas para 0 processamento de frases em português por monolíngues e bilíngues. Doze bilíngues tardios do par linguístico português brasileiro-inglês e 10 monolíngues do português brasileiro participaram do estudo. Os estímulos consistiram de 60 frases em inglês e frases equivalentes em português. Os participantes bilíngues leram as frases enquanto imagens funcionais do cérebro eram adquiridas em dois dias distintos enquanto os participantes monolíngues apenas leram as frases em português numa única sessão. Os dados foram analisados estatisticamente e revelam, em termos gerais, que a representação e o processamento da $L 1$ engajam uma rede complexa de áreas cerebrais em monolíngues e bilíngues. Os bilíngues, em comparação com os monolíngues, recrutaram áreas adicionais bilateralmente para lidar com os aspectos fonológicos e semânticos da L1. Tal resultado pode sugerir que ser bilíngue muda a forma como os indivíduos processam sua língua materna.

Palavras-chave: Processamento de frases. Monolíngues. Bilíngues. Compreensão leitora. Ressonância magnética funcional.

Abstract: This article presents part of a dissertation developed at the Center for Reading Studies at the Federal University of Santa Catarina in partnership with the Center for Cognitive Brain Imaging at Carnegie Mellon University (Pittsburgh, PA, USA). The study, of a cross-sectional, quantitative and exploratory nature, aimed at investigating Brazilian Portuguese monolingual brains and Brazilian Portuguese and English bilingual brains and their neuroanatomical response to the processing of written sentences. For the purposes of this article, we decided to concentrate on describing the results related to the objective of investigating the brain areas recruited for the processing of sentences in Portuguese by monolinguals and bilinguals. Twelve Brazilian Portuguese-English late bilinguals and ten Brazilian Portuguese monolinguals participated in the study. The stimuli consisted of 60 sentences in English and their translation-equivalent sentences in Portuguese. Bilingual participants read the sentences while functional images were acquired on two separate days while monolinguals only read the Portuguese sentences in a single session. Data were analyzed statistically and revealed, in general terms, that L1 representation and processing engages a complex network of brain areas in monolinguals and bilinguals. Bilinguals, in comparison with monolinguals, recruited additional bilateral areas for dealing with the phonological and semantic aspects of the L1. Such result may suggest that being bilingual changes the way individuals process their native language.

Keywords: Sentence processing. Monolinguals. Bilinguals. Reading comprehension. Functional magnetic resonance imaging.

\footnotetext{
1 O Núcleo de Estudos em Leitura (NEL) é um grupo de pesquisa cadastrado no Diretório de Grupos de Pesquisa do CNPq (dgp.cnpq.br/dgp/espelhogrupo/6618200615276721) desde 2002 e tem como objetivo principal desenvolver pesquisas na área de processamento e compreensão da linguagem escrita, incluindo tanto os aspectos cognitivos e neurocognitivos, como os instrucionais.
} 


\section{Introdução}

No nosso entendimento, a internacionalização de uma Universidade pode acontecer através de várias ações, descensionais ou ascensionais. Ações descensionais envolvem, por exemplo, convênios formais estabelecidos pelas secretarias de relações internacionais entre universidades brasileiras $\mathrm{e}$ aquelas do exterior. Nesse caso, pesquisadores interessados buscam, entre os convênios firmados, centros de pesquisas de seu interesse com quem possam estabelecer parcerias acadêmicas. Ações ascensionais, por outro lado, como a que deu fruto à presente pesquisa, nascem de interesses individuais dos próprios pesquisadores, que estabelecem colaborações com colegas de áreas afins no exterior.

A pesquisa aqui relatada resulta de parceria acadêmica estabelecida pela segunda autora deste trabalho com o pesquisador Marcel Adam Just da Carnegie Mellon University, em Pittsburgh, estado da Pensilvânia, nos Estados Unidos, desde o ano de 1994, anterior às facilidades da internet e à praticidade das mídias síncronas (por exemplo, webconferência) ou assíncronas (como e-mail), que permitem trocas acadêmicas em tempo real ou a critério dos interagentes, de forma dinâmica e eficiente. Por ocasião do primeiro contato, através do correio postal, Marcel Just conduzia estudos comportamentais, principalmente na área de processamento da linguagem e memória de trabalho, foco de interesse da segunda autora naquele momento. Em 1995, Marcel Just e sua então colaboradora Patricia Carpenter criaram o Center for Cognitive Brain Imaging (CCBI), laboratório que utiliza a neuroimagem, principalmente a ressonância magnética funcional, para a investigação de processos cognitivos. Desde então, a segunda autora mantém contatos regulares com Marcel Just, através de publicações conjuntas e/ou visitas acadêmicas (como pós-doutoramento) e/ou envio de orientandos de doutorado em bolsa PDSE (Programa de Doutorado Sanduíche no Exterior), o caso da primeira autora deste trabalho, que esteve naquele centro durante 12 meses para a coleta e análise de dados de neuroimagem da sua tese de doutoramento.

Vale ressaltar que ações de internacionalização, sejam elas descensionais ou ascensionais, não frutificam sem 0 fomento necessário para a sua realização. Nesse sentido, essa parceria acadêmica entre o Núcleo de Estudos em Leitura (NEL), coordenado pela segunda autora, com o CCBI prospera em razão de bolsas CAPES recebidas para que visitas acadêmicas fossem ali realizadas. Por exemplo, bolsa de estágio pósdoutoral para a segunda autora anteriormente, e bolsa PDSE para a primeira autora, mais recentemente.

Dentro do contexto acima exposto, este artigo apresenta um recorte de uma tese (BAILER, 2016) desenvolvida no Núcleo de Estudos em Leitura na Universidade Federal de Santa Catarina em parceria com o Center for Cognitive Brain Imaging na Carnegie Mellon University (Pittsburgh, PA, EUA). O estudo, de natureza transversal, quantitativa e exploratória, objetivou investigar cérebros de monolíngues do português-brasileiro e bilíngues do par linguístico português-brasileiro e inglês e sua resposta neuroanatômica ao processamento de frases escritas. Para os fins deste artigo, delimitou-se detalhar os resultados relativos ao objetivo de investigar as áreas cerebrais recrutadas para o processamento de frases em português por monolíngues e bilíngues.

O estudo contou com 10 participantes monolíngues do português-brasileiro e 12 participantes bilíngues do par linguístico portuguêsbrasileiro e inglês ${ }^{2}$. A hipótese relacionada ao objetivo é a de que os bilíngues apresentariam maior ativação em áreas localizadas no hemisfério direito, como o giro temporal superior, uma área tradicionalmente implicada no processamento léxico-semântico, em comparação aos monolíngues (KOVELMAN; BAKER;

\footnotetext{
2 Tal número pode ser considerado muito baixo se comparado ao número de participantes em estudos comportamentais. No entanto, tendo em mente o alto custo associado a experimentos com ressonância magnética funcional (fMRI), numa rápida busca na literatura, percebe-se que o tamanho da amostra deste estudo é similar a outros estudos com neuroimagem funcional.
} 
PETITTO, 2008; PARKER JONES et al., 2012; PALOMAR-GARCÍA et al., 2015).

Um grande número de estudos na literatura bilíngue comparou a atividade cerebral relacionada ao processamento da primeira versus da segunda língua dentre os mesmos indivíduos (KIM et al., 1997; ILLES et al., 1999; MARIAN et al., 2003; e BUCHWEITZ, 2006, entre outros). Apesar desse foco, as pesquisas não têm concentrado no estudo direto do processamento da linguagem nos cérebros de bilíngues comparados aos cérebros de monolíngues. Depois de uma busca árdua, apenas três estudos foram encontrados (KOVELMAN; BAKER; PETITTO, 2008; PARKER JONES et al., 2012; PALOMARGARCÍA et al., 2015). Esses estudos compararam a ativação cerebral de bilíngues à de monolíngues lendo em sua língua materna. Kovelman e colegas (2008) e Palomar-García e colegas (2015) conduziram estudos com bilíngues precoces, enquanto Parker Jones e colaboradores (2012) recrutaram uma amostra mista de bilíngues (três grupos de variadas idades de aquisição: de 1 a 15 anos de idade). O estudo de 2008 investigou monolíngues do inglês e bilíngues do par linguístico espanhol-inglês; o de 2012 examinou monolíngues do inglês e bilíngues com variadas línguas maternas e inglês como L2; e o estudo de 2015 investigou monolíngues do espanhol e bilíngues do par linguístico espanhol-catalão.

Esses três estudos apresentaram diferenças na condição bilíngues-monolíngues. Em Kovelman e colegas (2008), bilíngues demonstraram ativação no córtex frontal inferior esquerdo (BA44 e 45). Parker Jones et al. (2012) observaram maior ativação em seis áreas do hemisfério esquerdo: planum temporale, pré-central, temporal superior, pars opercularis, pars triangularis e ínsula. Palomar-García e colegas (2015) reportaram mais ativação no precúneo esquerdo e áreas temporais superiores direitas para a tarefa de nomear figuras; e ativação maior no giro temporal superior posterior direito para a escuta passiva de palavras. Apesar de diferenças metodológicas, monolíngues e bilíngues parecem recrutar áreas semelhantes para processar a linguagem. Entretanto, bilíngues parecem demonstrar mais ativação em tais áreas e recrutam outras áreas para processar sua L1.

Considerando esses dados, para o conhecimento das pesquisadoras, o estudo aqui apresentado é o primeiro a comparar monolíngues do português e bilíngues tardios do par linguístico português brasileiro-inglês. No que segue, apresentamos os detalhes metodológicos do estudo, seguidos pelos resultados e análise e por fim, as considerações finais.

\section{Método}

Esta seção descreve brevemente o método utilizado para investigar o processamento neural de frases em português por monolíngues e bilíngues. É importante destacar que os dados foram coletados enquanto a primeira autora deste artigo estava em seu doutorado sanduíche em uma universidade norteamericana, como mencionado anteriormente, portanto, o estudo obteve aprovação do comitê de ética dessa instituição (Carnegie Mellon University Institutional Review Board - IRB protocol HS14-474).

\subsection{Desenho do estudo}

Dez monolíngues do português participaram do estudo em duas sessões individuais enquanto doze bilíngues tardios do par linguístico português brasileiro-inglês participaram em três sessões individuais. No caso dos monolíngues, a primeira sessão envolvia o scan na máquina de fMRI. Já no caso dos bilíngues, as duas primeiras sessões envolviam os scans na máquina de $\mathrm{fMRI}$, cada dia em uma língua e essa ordem foi contrabalançada. A Figura 1 apresenta o desenho do estudo. 
Figura 1: Desenho do estudo

\begin{tabular}{|c|c|}
\hline Participantes monolíngues & Participantes bilíngues \\
\hline $1^{\text {a }}$ sessão & $1^{\text {a }}$ sessão \\
\hline $\begin{array}{l}\text { - Termo de consentimento; } \\
\text { - Questionário demográfico e de lateralidade; } \\
\text { - Instruções; } \\
\text { - fMRI em português; } \\
\text { - Teste de reconhecimento; } \\
\text { - Questionário de impressões. }\end{array}$ & $\begin{array}{l}\text { - Termo de consentimento; } \\
\text { - } \text { Questionário demográfico e de lateralidade; } \\
\text { - Instruções; } \\
\text { - } \text { fMRI em uma língua (ordem contrabalançada); } \\
\text { - } \text { Questionário de impressões. }\end{array}$ \\
\hline $2^{\mathrm{a}}$ sessão & $2^{\text {a }}$ sessão \\
\hline \multirow[t]{3}{*}{$\begin{array}{l}\text { - Questionário sobre o contexto linguístico do participante; } \\
\text { - } \quad \text { Teste de Capacidade em Leitura (TCL) em português; } \\
\text { - Questionário sobre o teste. }\end{array}$} & $\begin{array}{l}\text { - } \text { Termo de consentimento; } \\
\text { - Instruções; } \\
\text { - } \quad \text { fMRI na outra língua (ordem contrabalançada); } \\
\text { - } \quad \text { Teste de reconhecimento; } \\
\text { - } \text { Questionário de impressões. }\end{array}$ \\
\hline & $3^{\mathrm{a}}$ sessão \\
\hline & $\begin{array}{l}\text { - Teste de Capacidade em Leitura (TCL) em uma língua; } \\
\text { - Questionário sobre o teste; } \\
\text { - Questionário sobre o contexto linguístico do participante; } \\
\text { - Teste de proficiência (adaptação da parte de leitura do TOEFL); } \\
\text { - TCL na outra língua; } \\
\text { - Questionário sobre o teste. }\end{array}$ \\
\hline
\end{tabular}

Na primeira sessão com os monolíngues e nas duas primeiras sessões com os bilíngues, a pesquisadora leu os termos de consentimento livre e esclarecido, e na sequência, cada participante respondeu a um questionário demográfico e a um teste de lateralidade, ambos prática padrão do laboratório em que o estudo foi conduzido. A pesquisadora leu e explicou as instruções da tarefa que o participante faria dentro da máquina e para garantir que não houvesse nenhuma dúvida, cada participante teve a oportunidade de praticar a tarefa num simulador, que é uma réplica de uma máquina de fMRI. Na sequência, cada participante foi levado à sala do scanner real para realizar a tarefa que levava uma hora. Após o término da tarefa, o participante era levado à uma outra sala para fazer o teste de reconhecimento, prática comum no laboratório para garantir que o participante prestou atenção às frases enquanto realizou a tarefa, e também responder ao questionário de impressões. Para os bilíngues, a segunda sessão envolvia o mesmo procedimento, só que na outra língua, conforme recomendação de Grosjean (1998) para colocar o participante no modo monolíngue.
No último encontro, ou seja, na segunda sessão para os monolíngues e na terceira para os bilíngues, cada participante desempenhou testes comportamentais individualmente. Os monolíngues responderam a um questionário sobre seu contexto linguístico, desempenharam o Teste de capacidade de leitura, em português (TOMITCH, 2003, adaptado por BAILER, 2011) e responderam a um questionário retrospectivo do teste. Os bilíngues, além de receber - mesmo tratamento que os monolíngues, desempenharam também o Reading span test, em inglês (DANEMAN; CARPENTER, 1980) em ordem contrabalançada, e também responderam a uma versão adaptada da seção de leitura do TOEFL (Test of English as a Foreign Language - Educational Testing Service(C) para medir sua proficiência em leitura em inglês. Os participantes receberam recompensa financeira ao fim de cada sessão, como é prática recorrente em pesquisas científicas nos EUA. Vale destacar que cada participante recebeu também uma imagem estrutural do seu cérebro e assim que o trabalho foi concluído, uma cópia eletrônica da tese desenvolvida. 


\subsection{Participantes}

Em relação aos monolíngues do português brasileiro, 10 destros participaram do estudo. $\mathrm{Na}$ coleta de dados, possuíam idade média de 28 anos (intervalo de 21 a 38 anos), e vinham de uma diversidade de estados brasileiros (SC, PR, SP, ES, $\mathrm{PI}, \mathrm{CE}$ e PE). Os participantes reportaram não conseguir se comunicar em nenhuma segunda língua, apesar de oito terem tido contato com inglês, espanhol ou francês durante sua vida escolar. Dos dez participantes, quatro estavam na cidade norteamericana na ocasião da coleta de dados deste estudo para visitar amigos ou familiares por alguns dias; enquanto seis estavam na cidade para começar a aprender inglês. Em relação à sua escolaridade, sete participantes têm nível superior, um, nível técnico e dois, ensino médio completo.

Em relação aos bilíngues, 12 bilíngues tardios do par linguístico português brasileiro-inglês destros participaram do estudo. Na coleta de dados, possuíam idade média de 27 anos (intervalo de 20 a 32 anos), moravam nos EUA por um período médio de 2 anos (intervalo de 6 meses a 9 anos), vinham de uma diversidade de estados brasileiros (RS, SC, PR, $S P, M G, C E$ e PE), e a idade média de início da aprendizagem de inglês era 12,9 anos (intervalo de 7 a 22 anos). Todos os doze eram altamente proficientes na língua inglesa na época da coleta de dados. No teste de proficiência adaptado, os participantes exibiram uma média de 8,53 pontos (DP $=1,16$; intervalo $=6,7-10$ ).

Em relação à escolaridade, neste estudo os bilíngues apresentam um nível mais alto. Quatro dos 12 bilíngues estavam matriculados em cursos de doutorado e quatro em cursos de graduação à época da coleta de dados. Dos quatro restantes, dois já haviam concluído a graduação e dois, o doutorado. Oito dos doze já haviam realizado exames padronizados de proficiência na língua inglesa (TOEFL, IELTS) antes de entrar nos EUA e os quatro restantes tiveram sua proficiência atestada pela universidade brasileira de onde vêm. Para validar sua proficiência formalmente, os participantes tiveram de desempenhar uma versão adaptada do TOEFL. Os participantes obtiveram uma nota média de 8,53 (intervalo $=6,7-10)$. Nos questionários, revelaram o uso maior do inglês no seu dia a dia, mas também usavam o português (em menor escala).

\subsection{Paradigma experimental}

Os participantes monolíngues leram 60 frases em português enquanto os bilíngues, além de lerem as 60 frases em português, leram suas versões equivalentes em português (ex.: The diplomat negotiated at the embassy/O diplomata negociou na embaixada) enquanto imagens cerebrais funcionais eram adquiridas. As frases foram apresentadas em branco num fundo preto. Cada frase era apresentada em partes, uma de cada vez, conforme a Figura 2. Os participantes foram instruídos a ler cada parte da frase silenciosamente e pensar sobre o significado de cada palavra, construindo uma representação mental vívida da frase. Após o ponto final, deveriam continuar a pensar sobre a frase e seus elementos. Quando o X aparecesse, deveriam se concentrar nele, relaxando e limpando a mente, o que chamamos de fixação. Cada frase aparecia quatro vezes, de forma randomizada.

Figura 2: Representação esquemática do paradigma experimental

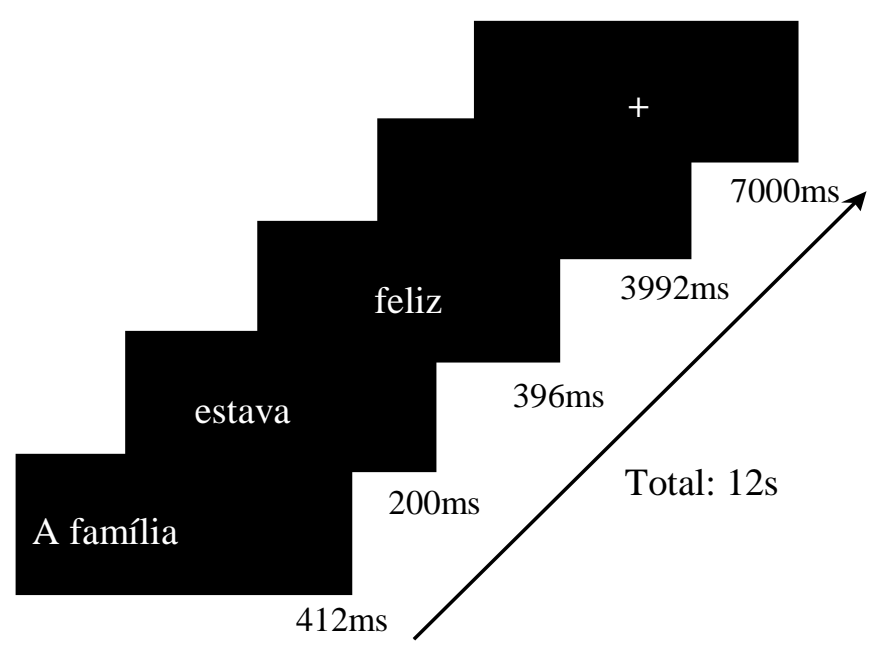


Neste estudo, entendemos processamento como os processos que ocorrem online enquanto os participantes leem as frases silenciosamente dentro do scanner. Por sua vez, representação é o que se torna ativado através de nossos pensamentos, a percepção e compreensão de palavras e frases. Como explicado por Lindquist (2015, comunicação pessoal), a representação cerebral é a base física de uma experiência mental ou estrutura de informação. Assim, neste estudo, procuramos elucidar a representação da língua materna, neste caso o português em monolíngues e bilíngues. Além disso, procuramos entender os processos que ocorreram no cérebro enquanto nossos participantes estavam pensando sobre o significado das frases a que foram apresentados. Nosso estudo está no nível microestrutural da compreensão do texto (KINTSCH; VAN DIJK, 1978) e ao nível literal de compreensão (GAGNÉ; YEKOVICH; YEKOVICH, 1993). Nossas frases abrangem conteúdos simples, concretos, literais e culturalmente inespecíficos, bem como conceitos básicos de nível (ROSCH et al., 1976), como carro, escola e flor. Nossa abordagem centrouse na composição semântica, uma vez que os indivíduos ativam características de conceitos durante o processamento de frases.

Após o fim da sessão de fMRI, os participantes realizaram o teste de reconhecimento para assegurar que prestaram total atenção às frases durante $a$ tarefa no fMRI. Os resultados indicam que os participantes puderam processar as frases ativamente, pois puderam distinguir frases vistas e não vistas com uma acurácia média de $97 \%$.

Em relação aos testes de capacidade de memória de trabalho (Testes de Capacidade em Leitura), os participantes monolíngues exibiram uma média de 2,6 $(\mathrm{DP}=0,45$; intervalo $=2-3,5)$, enquanto os participantes bilíngues, uma média de 3,08 (DP = $0,92$; intervalo $=2-5,5)$ em português e uma média de $3,25(D P=1,03 ;$ intervalo $=2-5,5)$ em inglês. Conforme esperado, os resultados dos bilíngues nos dois testes correlacionaram de forma forte $e$ significativa $(r=0,879, p=0,000)$. Apesar de os resultados apresentaram uma forte correlação, é interessante notar que a média mais alta é em inglês, a segunda língua.

Levando em consideração o contexto em que os participantes viviam na época da coleta de dados, eles estavam imersos na cultura norte-americana: trabalhavam, estudavam, interagiam com a maioria das pessoas em inglês. O português era usado apenas para comunicação com a família e amigos no Brasil, brasileiros na cidade, ou para ler as notícias brasileiras online. Tais pontuações comparáveis parecem confirmar a proficiência dos nossos participantes na L2.

\subsection{Detalhes do fMRI}

Imagens funcionais foram adquiridas num Siemens Verio 3T no Scientific Imaging \& Brain Research Center (SIBR) da Carnegie Mellon University. Imagens foram geradas a partir de 16 fatias oblíquas-axiais de $5 \mathrm{~mm}$ de espessura (com 1 $\mathrm{mm}$ de diferença entre as fatias). A matriz de aquisição foi de 64 × 64 com 3,125 x 3,125 x 6 mm voxels, permitindo a obtenção de muitas observações do nível de ativação em cada voxel, gerando uma imagem de um amplo volume do cérebro em alta resolução. A apresentação das frases foi feita com o software CogLab, que sincroniza a aquisição de imagens com os estímulos visuais. Um projetor LCD projetou os estímulos visuais numa tela na parte de trás da máquina. Os participantes viram essa tela por meio de um sistema de espelho inclinado.

\subsection{Processamento e análise dos dados de fMRI}

Os dados foram analisados com o SPM8 (Wellcome Trust Centre for Neuroimaging, University College London). Os procedimentos padrão da análise de dados de fMRI foram feitos, como a correção do movimento de cabeça, a normalização para o modelo do Montreal Neurological Institute, e a regularização para reduzir ruído espacial. Análises estatísticas foram conduzidas no cérebro inteiro no nível da sentença em dados individuais e de grupo 
usando o modelo linear generalizado (do inglês, GLM). Análises de grupo foram conduzidas usando o modelo de efeitos aleatórios (do inglês, randomeffects model). Mapas estatísticos foram sobrepostos a um modelo anatômico e as áreas foram nomeadas a partir do Automated anatomical labeling (AAL, TZOURIO-MAZOYER et al., 2002).

Imagens de contraste foram geradas (leitura > fixação) para cada participante em cada língua e a análise de segundo nível (entre participantes) foi feita nessas imagens de contraste com um teste t pareado com as diferenças individuais como regressores no modelo. Os testes estatísticos foram desempenhados pelo time do Center for Cognitive Brain Imaging (CCBI-Carnegie Mellon University). Conforme Amaro Jr. e Barker (2006, p. 220, tradução nossa), "um experimento com fMRI depende de técnicas e metodologias derivadas de diferentes áreas do conhecimento, tornando-o intrinsicamente multidisciplinar".

\section{Resultados e Discussão}

Nesta seção, apresentamos os resultados, com o auxílio de figuras e tabelas, das análises estatísticas dos dados referentes aos participantes monolíngues e bilíngues e as áreas cerebrais recrutadas para o processamento de frases em português, seguidos da análise desses dados em relação à literatura. A primeira subseção apresenta e discute os resultados da análise no nível da sentença, advindos de uma análise estatística GLM (modelo linear geral). A segunda subseção apresenta e discute os resultados da análise no nível da palavra, advindos de uma análise estatística com modelos de regressão e correlação média em pares.

\subsection{Análise do nível da sentença}

O contraste de monolíngues e bilíngues lendo em português maior que a fixação foi conduzido separadamente para cada um dos 10 participantes, no caso dos monolíngues, e cada um dos 12 participantes, no caso dos bilíngues, e na sequência, a média entre os participantes foi realizada com 0 teste t pareado. Assim, é possível observar as áreas ativadas por monolíngues e por bilíngues ao ler em português, conforme Figura 3 e Tabelas 1 e 2.

Figura 3: Áreas de ativação correlacionadas com a leitura em português em monolíngues e bilíngues
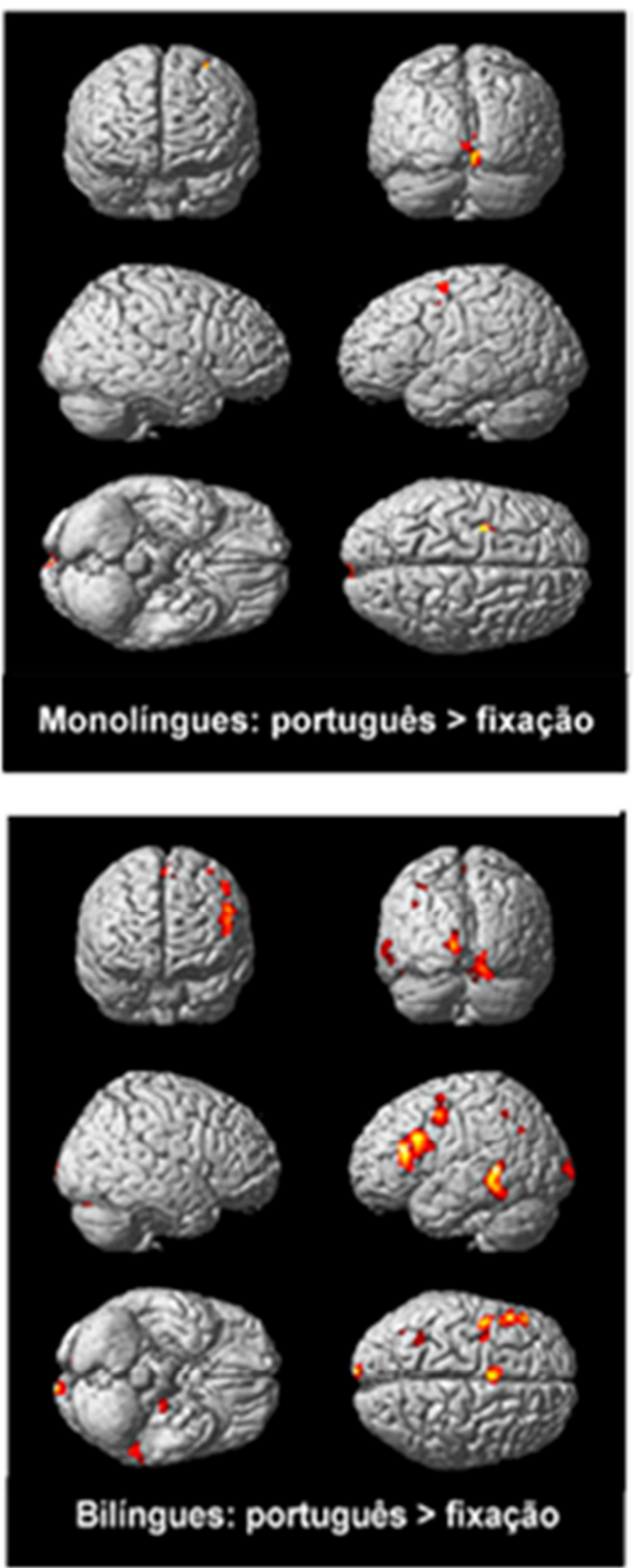

Nota: Monolíngues: SPM8; $p<0,001$, não corrigidos; $T=4,30$; mínimo agrupamento de voxels $=15$. Bilíngues: SPM8; $p$ $<0,001$, não corrigidos; $T=4,02$; mínimo agrupamento de voxels $=15$. 
Tabela 1: Áreas de ativação correlacionadas com a leitura em português em monolíngues

\begin{tabular}{|c|c|c|c|c|c|c|}
\hline \multicolumn{7}{|c|}{ Leitura em português em monolíngues > Fixação } \\
\hline Centróide e ativação adjacente & $\begin{array}{c}\text { Tamanho do } \\
\text { grupo (voxels) }\end{array}$ & $T(10)$ & BA & \multicolumn{3}{|c|}{ Coordenada MNI } \\
\hline & & & & $x$ & $y$ & $z$ \\
\hline \multicolumn{7}{|l|}{ Frontal } \\
\hline Área frontal média esquerda & 35 & 5,19 & BA6 & -28 & 4 & 46 \\
\hline Área frontal superior esquerda & 27 & 5,95 & BA4 & -32 & -4 & 66 \\
\hline Cingulado esquerdo & 19 & 5,69 & BA24 & -16 & -8 & 32 \\
\hline \multicolumn{7}{|l|}{ Occipital } \\
\hline Área lingual direita & 58 & 5,68 & BA18 & 8 & -84 & -8 \\
\hline Calcarino esquerdo & 34 & 5,17 & $\mathrm{BA} 17$ & 2 & -100 & 0 \\
\hline $\begin{array}{l}\text { Área occipital superior } \\
\text { esquerda }\end{array}$ & & 4,67 & BA17 & 8 & -98 & 8 \\
\hline Lingual direito & & 4,39 & BA18 & 6 & -96 & -8 \\
\hline \multicolumn{7}{|l|}{ Subcortical } \\
\hline Tálamo esquerdo & 45 & 5,28 & & -18 & -38 & 12 \\
\hline $\begin{array}{l}\text { Caudado posterior } \\
\text { esquerdo }\end{array}$ & & 4,49 & & -26 & -38 & 6 \\
\hline \multicolumn{7}{|l|}{ Cerebelo } \\
\hline Cerebelo esquerdo & 17 & 5.43 & & -8 & -34 & -12 \\
\hline
\end{tabular}

Nota: Grupos de voxels significantes com $p<0,001$, não corrigidos, $T=4,30$. Contraste de grupo entre monolíngues lendo em português e fixação. Os rótulos de região se aplicam à toda a extensão do grupo com o pico máximo designado pelo primeiro local citado. Valores $T$ e coordenadas $\mathrm{MNI}$ se referem ao voxel com pico de ativação em cada grupo. Os rótulos são dados no sistema AAL (Automated Anatomical Labeling System) conforme implementado no SPM8.

Conforme dados da Tabela 1, monolíngues lendo em português ativaram 7 grupos de voxels em áreas frontais esquerdas, occipitais bilaterais, regiões subcorticais esquerdas e o cerebelo esquerdo. Um total de 177 voxels foram ativados no hemisfério esquerdo enquanto 58 no hemisfério direito. O maior agrupamento de voxels estava na área lingual direita (58 voxels) e no calcarino esquerdo com picos na região occipital superior e lingual direita (34 voxels). Tais áreas são normalmente recrutadas para a identificação e reconhecimento de palavras (MECHELLI et al., 2000; ABUTALEBI et al., 2001). Três agrupamentos no lobo frontal esquerdo: frontal superior (BA4, 27 voxels), cingulado (BA24, 19 voxels), e frontal médio (BA6, 35 voxels) estão tradicionalmente envolvidos no processamento fonológico e funções de memória de trabalho (BOLGER et al., 2005; BLEDOWSKI et al., 2009). Um agrupamento no tálamo que se estende ao caudado posterior também foi recrutado (45 voxels). De acordo com Crinion e colegas (2006), o tálamo e o caudado desempenham "um papel fundamental para controlar e selecionar sequências motores automáticas como aquelas necessárias para articulação" (p.1540). Bialystok e colegas (2009) explicam que as estruturas dos gânglios da base, incluindo o caudado, são recrutados para seleção da língua, processos de troca, planejamento linguístico e seleção lexical. Alguns estudos sugerem que o caudado esquerdo está envolvido no controle lexical-semântico em sujeitos monolíngues e bilíngues (CRINION et al., 2006). Entretanto, o papel de tais estruturas subcorticais na compreensão leitora de monolíngues não está bem documentada. Assim, o presente estudo contribui para esta lacuna na literatura. 
Tabela 2: Áreas de ativação correlacionadas com a leitura em português em bilíngues

\begin{tabular}{|c|c|c|c|c|c|c|}
\hline \multicolumn{7}{|c|}{ Leitura em português em bilíngues > Fixação } \\
\hline Centróide e ativação adjacente & $\begin{array}{c}\text { Tamanho do grupo } \\
\text { (voxels) }\end{array}$ & $T(12)$ & BA & \multicolumn{3}{|c|}{ Coordenada MNI } \\
\hline & & & & $x$ & $y$ & $z$ \\
\hline \multicolumn{7}{|l|}{ Frontal } \\
\hline $\begin{array}{l}\text { Área frontal inferior esquerda } \\
\text { (opercularis) }\end{array}$ & 901 & 6,76 & BA 44 & -48 & 18 & 32 \\
\hline $\begin{array}{l}\text { Área frontal inferior } \\
\text { esquerda (triangularis) }\end{array}$ & & 6,27 & BA45 & -42 & 26 & 14 \\
\hline $\begin{array}{l}\text { Área frontal inferior } \\
\text { esquerda (opercularis) }\end{array}$ & & 6,16 & BA44 & -38 & 8 & 22 \\
\hline Área motor suplementar esquerda & 195 & 6,27 & BA6 & -6 & 8 & 56 \\
\hline Área pré-central esquerda & 144 & 5,68 & BA6 & -46 & -2 & 48 \\
\hline Sulco frontal superior direito & 124 & 6,01 & BA24 & 22 & -2 & 34 \\
\hline Putâmen direito & & 4,96 & & 30 & -2 & 12 \\
\hline Caudado direito & & 5,80 & & 24 & -6 & 20 \\
\hline Área frontal média esquerda & 27 & 5,58 & & -22 & -6 & 26 \\
\hline Área pré-central esquerda & 34 & 4,95 & BA6 & -36 & 0 & 62 \\
\hline Área pré-central direita & 20 & 5,48 & & 36 & -6 & 26 \\
\hline \multicolumn{7}{|l|}{ Parietal } \\
\hline $\begin{array}{l}\text { Área parietal inferior esquerda } \\
\text { (sulco intraparietal) }\end{array}$ & 91 & 5,01 & BA7 & -30 & -54 & 46 \\
\hline Angular esquerdo & 16 & 4,66 & BA 39 & -38 & -66 & 36 \\
\hline \multicolumn{7}{|l|}{ Temporal } \\
\hline Hipocampo esquerdo & 1,001 & 7,35 & & -20 & -46 & 2 \\
\hline $\begin{array}{l}\text { Área temporal média } \\
\text { esquerda }\end{array}$ & & 6,87 & & -34 & -52 & 8 \\
\hline $\begin{array}{l}\text { Área parahipocampal } \\
\text { esquerda }\end{array}$ & & 6,56 & & -28 & -56 & 2 \\
\hline Hipocampo direito & 287 & 7,05 & & 30 & -38 & 6 \\
\hline Hipocampo direito & & 5,85 & BA20 & 36 & -42 & 0 \\
\hline Hipocampo direito & & 5,81 & BA19 & 22 & -40 & 6 \\
\hline Hipocampo esquerdo & 43 & 5,02 & BA36 & -22 & -20 & -20 \\
\hline Hipocampo esquerdo & 16 & 5,38 & & -30 & -34 & -6 \\
\hline \multicolumn{7}{|l|}{ Occipital } \\
\hline Áreal lingual direita & 211 & 5,59 & BA18 & 16 & -80 & -16 \\
\hline Calcarino direito & & 4,66 & & 18 & -92 & -4 \\
\hline Área occipital média esquerda & 136 & 5,43 & BA18 & -8 & -106 & 8 \\
\hline Área lingual esquerda & 48 & 4,45 & BA18 & -8 & -82 & -8 \\
\hline $\begin{array}{l}\text { Cingulado superior esquerdo } \\
\text { (calcarino) }\end{array}$ & 17 & 4,41 & BA31 & -6 & -70 & 12 \\
\hline \multicolumn{7}{|l|}{ Cerebelo } \\
\hline Cerebelo direito & 22 & 4,79 & & 30 & -68 & -32 \\
\hline
\end{tabular}

Nota: Grupos de voxels significantes com $\mathrm{p}<0,001$, não corrigidos, $\mathrm{T}=4,02$. Contraste de grupo entre bilíngues lendo em português e fixação. Os rótulos de região se aplicam à toda a extensão do grupo com o pico máximo designado pelo primeiro local citado. Valores $\mathrm{T}$ e coordenadas $\mathrm{MNI}$ se referem ao voxel com pico de ativação em cada grupo. Os rótulos são dados no sistema AAL (Automated Anatomical Labelina Svstem) conforme imblementado no SPM8.

De acordo com a Tabela 2, ler em português engajou também o cerebelo esquerdo (17 voxels) em monolíngues. O papel do cerebelo como coordenador das funções motoras é bem estabelecido na literatura, mas de acordo com De Smet e colegas (2013), estudos têm descoberto o papel do cerebelo na modulação de processamento cognitivo, linguístico e afetivo, como no "aprendizado associativo não-motor, memória de trabalho, habilidades visuoespaciais, fluência verbal, sintaxe, leitura e escrita" (p. 339). Cabeza e Nyberg (2000), numa revisão de 275 estudos com PET e fMRI, atribuíram ativação cerebelar para "o nível articulatório da produção de fala" (p. 15) e "processos de busca de memórias" ( $p$. 21). No entanto, o papel específico desta estrutura na compreensão leitora ainda não é bem entendida (DE SMET et al., 2013) e o presente estudo parece contribuir para esta lacuna.

Já os bilíngues lendo em português ativaram 18 grupos de voxels nos quatro lobos do cérebro, bilateralmente. Um total de 2.669 voxels foram ativados no hemisfério esquerdo enquanto 64 no 
hemisfério direito. O maior agrupamento estava na região do hipocampo, no lobo temporal, bilateralmente (total de 1.347 voxels), que é tradicionalmente implicado na recuperação de memórias e considerado "um potencial contribuintechave para funções cognitivas que requerem a integração online de múltiplas fontes de informação, como o processamento da linguagem" (DUFF \& BROWN-SCHMIDT, 2012, p.1). Grandes agrupamentos localizaram-se em áreas de associação visual no lobo occipital (BA18 e 19, um total de 412 voxels) regularmente envolvidos em processos ortográficos (BOLGER et al., 2005). O sulco intraparietal também foi recrutado, tipicamente associado com processamento visuoespacial (NEWMAN et al., 2003), possivelmente por causa da geração de imagens visuais das ações presentes nas frases. Além do cerebelo direito (22 voxels), um pequeno agrupamento de voxels importante para a compreensão leitora foi ativado na região angular esquerda (16 voxels). De acordo com Shaywitz e Shaywitz (2005), tal área é relacionada à conversão grafema-fonema. Stoeckel e colegas (2009) demonstraram em seu estudo que o giro angular também está associado à memória semântica.

Para investigar se há diferenças no processamento de frases em português por monolíngues e bilíngues, a ativação cerebral de cada grupo lendo em português foi contrastada com a ativação durante o período de fixação. Esta análise de segundo nível foi feita com teste $t$ de duas amostras "para comparar níveis médios durante ativação versus níveis médios durante fixação" (PAVLICOVÁ; CRESSIE; SANTNER, 2006, p. 275, tradução nossa) em duas amostras independentes. Assim, é possível observar que áreas estavam ativas enquanto monolíngues estavam lendo frases em português em contraste com bilíngues; e que áreas estavam ativas quando bilíngues estavam lendo em português em contraste com monolíngues, conforme ilustram a Figura 4 e a Tabela 3.
Figura 4: Contraste de ativação cerebral de monolíngues $>$ bilíngues e de bilíngues > monolíngues lendo em português
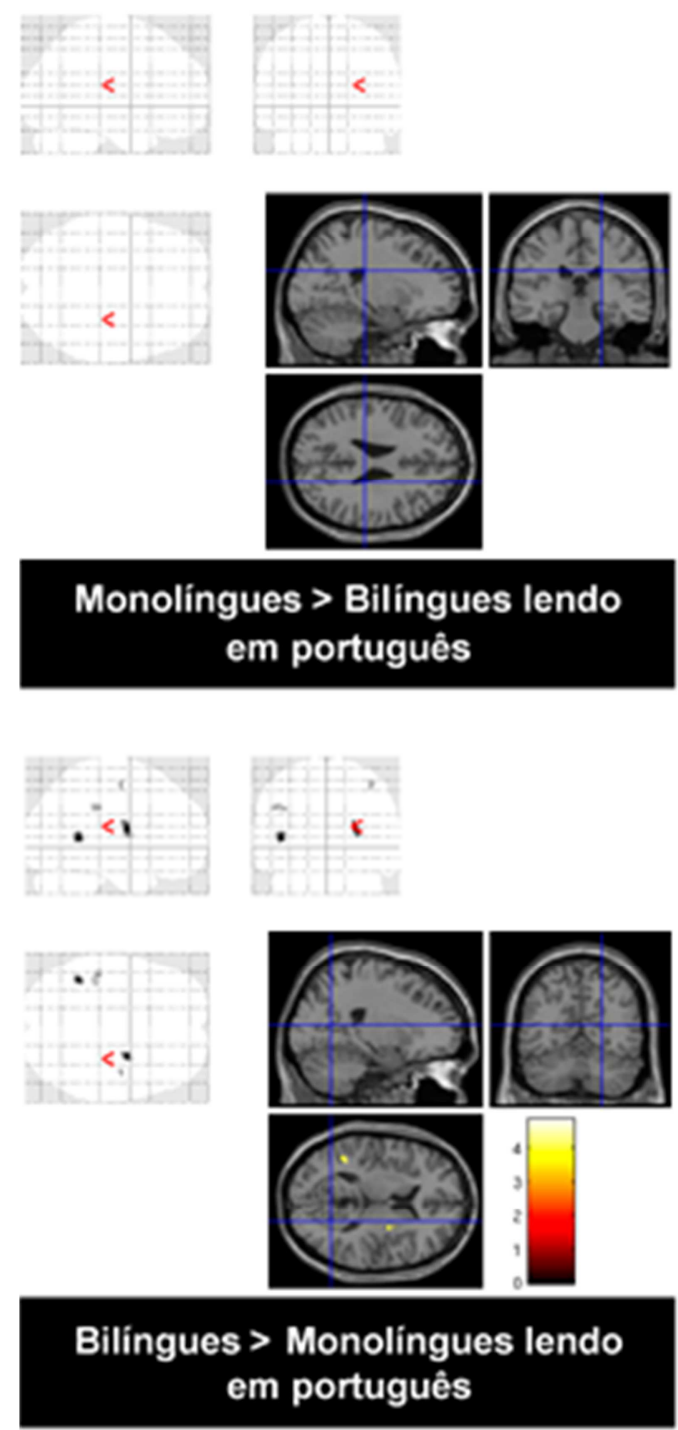

Nota: SPM8; $\mathrm{p}<0,001$, não corrigidos; $\mathrm{T}=3,55$; mínimo agrupamento de voxels $=5$. 
Tabela 3: Áreas de contraste de ativação cerebral de monolíngues > bilíngues e de bilíngues > monolíngues lendo em português

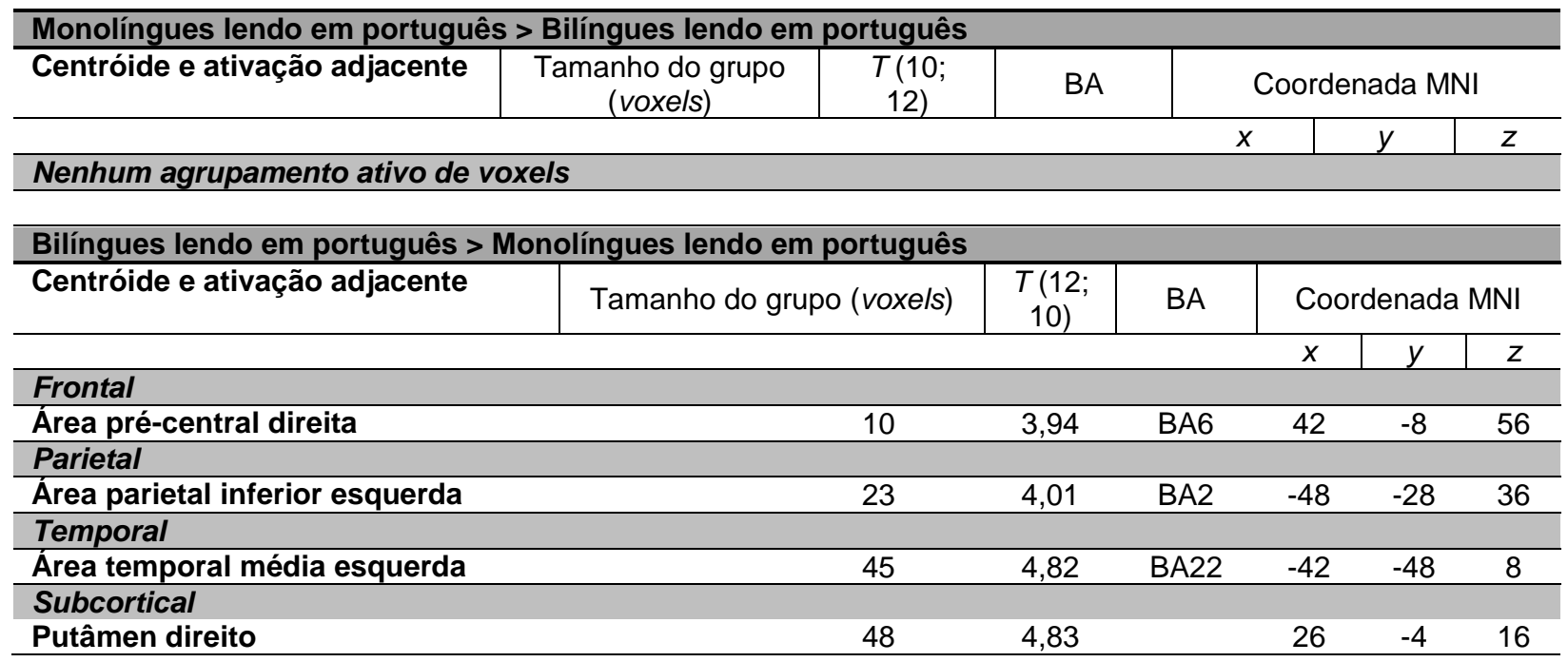

Nota: Grupos de voxels significantes com $p<0,001$, não corrigidos, $T=3,55$. Contraste de grupo entre monolíngues lendo em português e bilíngues lendo em português. Os rótulos de região se aplicam à toda a extensão do grupo com o pico máximo designado pelo primeiro local citado. Valores T e coordenadas MNI se referem ao voxel com pico de ativação em cada grupo.

Os rótulos são dados no sistema AAL (Automated Anatomical Labeling System) conforme implementado no SPM8.

O contraste monolíngues-bilíngues lendo em português sugere que monolíngues não ativaram nenhuma área além daquelas ativadas por bilíngues, já que nenhuma diferença foi encontrada (figura 4, tabela 3), exatamente como no estudo de Kovelman e colegas (2008). Por outro lado, o contraste bilínguesmonolíngues lendo em português demonstrou ativação de agrupamentos pequenos de voxels em áreas bilaterais. O maior agrupamento teve seu pico no putâmen direito (48 voxels), uma região que precisa de mais pesquisas para desvelar seu papel na compreensão leitora (BOHSALI et al., 2015). A região temporal média esquerda (BA 22) recrutada é tipicamente engajada no acesso semântico e processamento fonológico (DEHAENE, 2009). A área parietal inferior esquerda está normalmente envolvida com processamento fonológico e retenção de informação linguística no curto prazo em estudos de complexidade sintática (KELLER; CARPENTER; JUST, 2001) e efeitos de trava-língua (KELLER; CARPENTER; JUST, 2003) em compreensão de frases em monolíngues; com o mapeamento entre os sistemas ortográfico, fonológico e semântico em processamento de linguagem em monolíngues (HERNANDEZ et al., 2015), bem como na manutenção de representações e funções de memória de trabalho (BIALYSTOK et al., 2009). Em relação ao menor agrupamento, acredita-se que a região pré-central direita está envolvida em articulação silenciosa. Parker Jones e colegas (2012) também reportam ativação nessa área, mas no hemisfério esquerdo, para bilíngues comparados aos monolíngues lendo em sua língua materna (inglês).

Nossos resultados sugerem que bilíngues engajam mais áreas corticais para o processamento fonológico e semântico (BOLGER et al., 2005) da sua L1. Ademais, os dados parecem indicar que bilíngues engajam mais a rede fonológica que os monolíngues ao ler em sua língua materna. Tal resultado pode sugerir que ser bilíngue muda a forma como a L1 é processada (BIALYSTOK et al., 2009).

As imagens cerebrais de monolíngues e bilíngues lendo frases em português foram sobrepostas para permitir a visualização de áreas envolvidas na leitura em português nas duas amostras de participantes, conforme ilustra a Figura 5. 
Figura 5: Sobreposição de áreas de monolíngues e bilíngues lendo em português contrastado com fixação
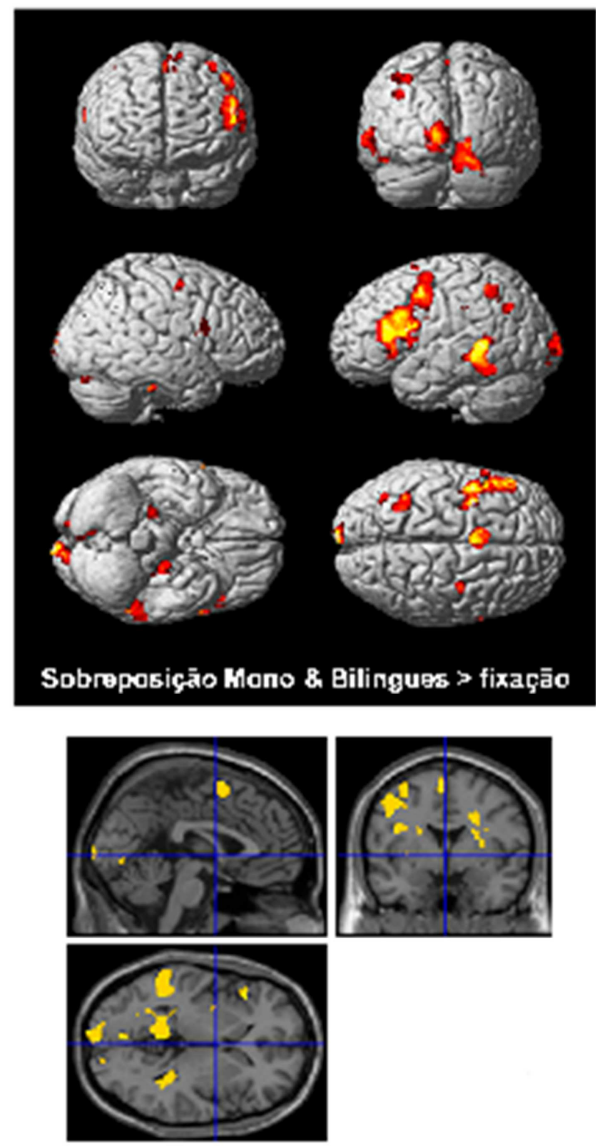

Nota: SPM8; $p<0,001$, não corrigidos; $T=3,55$; mínimo agrupamento de voxels $=5$.

É possível observar uma sobreposição em áreas frontais superiores esquerdas, temporais médias esquerdas e pequenos agrupamentos nas áreas parietais esquerdas, além de poucos agrupamentos em áreas do hemisfério direito, com destaque para um agrupamento na região occipital direita, maior que no hemisfério esquerdo, que é mais próximo do cerebelo. Apesar de usarem tarefas essencialmente distintas, Kovelman e colegas (2008) também encontraram sobreposição nas áreas recrutadas por monolíngues e bilíngues lendo frases e julgando sua plausibilidade em sua L1. Do mesmo modo, Parker Jones e colaboradores (2012) observaram um grau de sobreposição nas regiões cortical engajadas por monolíngues e bilíngues nomeando figuras, lendo palavras silenciosamente e desempenhando tarefas de decisão lexical.
Bialystok e colegas (2009) revelaram que bilíngues adultos normalmente levam mais tempo para recuperar palavras que monolíngues, e gerar menos respostas quando solicitados a listas palavras por uma letra inicial específica. Bilíngues exibem mais processos relacionados ao controle executivo da linguagem principalmente porque têm de lidar com candidatos da L1 e da L2 que estão simultaneamente ativados (SCHWARTZ \& KROLL, 2006). Monolíngues não precisam lidar com tal competição nos seus cérebros. Parker Jones et al. (2012) elucidam que bilíngues, por saber as palavras para um conceito em duas línguas, têm de seletivamente ativar a línguaalvo tentando minimizar a competição pela seleção da palavra de equivalentes de tradução na língua nãoalvo. Também, monolíngues usam a mesma língua diariamente enquanto bilíngues usam duas, a razão pela qual as palavras em cada uma das línguas dos bilíngues são menos usadas que as mesmas palavras na única língua que um monolíngue fala.

Assim, partimos para a seção de análise dos dados no nível da palavra, para nas considerações finais retomar os principais achados acerca da representação e do processamento da $L 1$ no cérebro de monolíngues e da L1 e da L2 no cérebro de bilíngues.

\subsection{Análise no nível da palavra}

A partir da análise de estabilidade ${ }^{3}$, examinouse a diferença no local de representação do português quando bilíngues e monolíngues leem frases (Figura 6). Hit maps foram gerados com os voxels mais estáveis entre todos os participantes do estudo. Conforme Mason e Just (2015), acredita-se que tais voxels são consistentemente seletivos ao processamento de palavras em português no contexto de frases.

\footnotetext{
${ }^{3}$ A análise de estabilidade foca nos voxels mais estáveis, pois se assume que apenas esses voxels fornecem informações sobre a representação neural de cada língua. A estabilidade de um voxel foi calculada como a correlação média em pares entre as palavras em cada língua nas quatro apresentações de cada sentença.
} 
Figura 6: Agrupamentos de voxels mais estáveis para monolíngues e bilíngues lendo em português
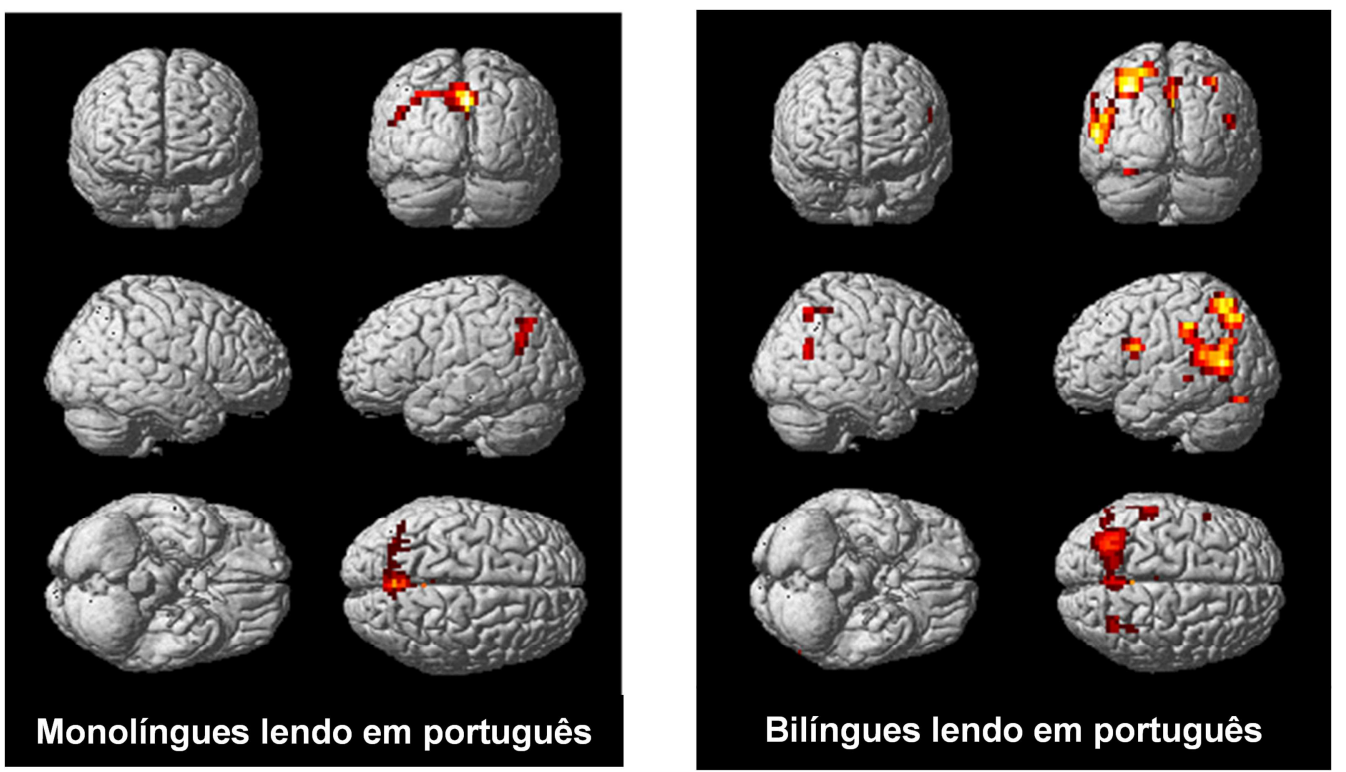

Tabela 4: Estabilidade de grupo para monolíngues e bilíngues lendo em português

\begin{tabular}{|c|c|c|c|c|c|}
\hline \multicolumn{6}{|c|}{ Voxels mais estáveis para leitura em português - monolíngues } \\
\hline Centróide e ativação adjacente & $\begin{array}{l}\text { Tamanho do } \\
\text { grupo (voxels) }\end{array}$ & $\mathrm{BA}$ & \multicolumn{3}{|c|}{ Coordenada MNI } \\
\hline & & & $x$ & $y$ & $z$ \\
\hline \multicolumn{6}{|l|}{ Parietal } \\
\hline Precúneo esquerdo & 431 & BA7/31 & 0,125 & $-58,875$ & 34 \\
\hline \multicolumn{6}{|c|}{ Voxels mais estáveis para leitura em português - bilíngues } \\
\hline Centróide e ativação adjacente & $\begin{array}{l}\text { Tamanho do } \\
\text { grupo (voxels) }\end{array}$ & BA & \multicolumn{3}{|c|}{ Coordenada MNI } \\
\hline & & & $x$ & $y$ & $z$ \\
\hline \multicolumn{6}{|l|}{ Frontal } \\
\hline Área frontal inferior esquerda & 55 & BA44/9/6 & $-49,875$ & 6,75 & 22 \\
\hline Área frontal superior esquerda & 8 & BA8 & $-21,75$ & 34,875 & 46 \\
\hline Área frontal média esquerda & 7 & BA6 & $-40,5$ & $-2,625$ & 52 \\
\hline Área frontal média esquerda & 4 & BA9 & $-40,5$ & 38 & 28 \\
\hline Área frontal inferior direita & 4 & BA6 & 50,125 & 6,75 & 34 \\
\hline \multicolumn{6}{|l|}{ Parietal } \\
\hline Precúneo esquerdo & 907 & $\mathrm{BA} 7 / 31$ & 0,125 & $-58,875$ & 34 \\
\hline Área parietal superior direita & 54 & $\mathrm{BA} 7 / 40$ & 31,375 & -62 & 52 \\
\hline Área fusiforme esquerda & 26 & BA19 & $-31,125$ & $-74,5$ & -20 \\
\hline Área angular direita & 2 & BA19/39 & 40,75 & $-71,375$ & 40 \\
\hline \multicolumn{6}{|l|}{ Temporal } \\
\hline Área temporal média direita & 26 & BA39 & 43,875 & -62 & 22 \\
\hline Área temporal inferior esquerda & 3 & BA37 & $-46,75$ & $-55,75$ & -14 \\
\hline
\end{tabular}

Nota: Grupos de voxels estáveis, dados regularizados, height threshold $=0,75$. Os rótulos de região se aplicam à toda a extensão do grupo com o pico máximo designado pelo primeiro local citado. Coordenadas MNI se referem ao voxel com pico de ativação em cada grupo. Os rótulos são dados no sistema AAL (Automated Anatomical Labeling System) conforme implementado no SPM8.

Os resultados demonstram que enquanto monolíngues apresentaram voxels estáveis apenas numa região do hemisfério esquerdo, bilíngues apresentaram estabilidade em uma variedade de áreas nos lobos frontal, parietal e temporal, um total de 1.096 voxels estáveis, 1.010 no hemisfério esquerdo e 86 no hemisfério direito. Regiões frontais inferiores, médias e superiores correspondentes às BA6, 8, 9 e 44 foram recrutadas, tradicionalmente associadas aos processos semânticos e fonológicos (BOLGER et al., 2005). A maioria dos voxels (989: 933 no hemisfério esquerdo e 56 no direito) localizados no lobo parietal englobam as áreas BA7/31, 7/40, 19 e 19/39. Tais áreas parecem estar 
envolvidas em processos fonológicos e ortográficos. Há 29 voxels estáveis na região temporal (BA 37 e 39), áreas normalmente implicadas no acesso semântico e análise visual (DEHAENE, 2009).

Curiosamente, monolíngues apresentaram 431 voxels estáveis nas mesmas coordenadas que os bilíngues (907 voxels do total de 1.096). Os resultados corroboram a inferência de que bilíngues recrutam mais áreas cerebrais, mais bem distribuídas, para ler sua língua materna. O precúneo tem sido associado ao imaginário visual, à recordação de memória episódica e tomada de perspectiva (CAVANNA \& TRIMBLE, 2006). Sua ativação estável pode estar refletindo os três processos, já que os participantes estavam lendo frases silenciosamente e foram instruídos a gerar representações mentais vívidas do significado de cada sentença.

\section{Considerações finais}

Para resumir, a resposta do nosso objetivo relacionado às áreas cerebrais recrutadas para o processamento de frases em português por monolíngues e bilíngues é parcialmente consistente com nossa hipótese inicial. Com base na literatura (KOVELMAN; BAKER; PETITTO, 2008; PARKER JONES et al., 2012; PALOMAR-GARCÍA et al., 2015), esperávamos que os bilíngues apresentariam maior ativação em comparação aos monolíngues e que o cérebro bilíngue apresentaria maior ativação em áreas localizadas no hemisfério direito, como o giro temporal superior, uma área tradicionalmente implicada no processamento léxico-semântico. Apesar de não termos encontrado ativação no giro temporal superior, nossos resultados revelam que os bilíngues engajam uma rede de áreas mais complexa para processar sua L1, e que essas áreas estão localizadas em regiões do hemisfério direito, como o putâmen e a área pré-central, e em regiões do hemisfério esquerdo, como a área temporal média e a região parietal inferior, reforçando que bilíngues, comparados aos monolíngues recrutam áreas bilaterais adicionais para processar sua língua materna.
Os resultados do presente estudo sugerem que bilíngues engajam mais áreas corticais para 0 processamento fonológico e semântico (BOLGER et al., 2005) da sua língua materna. Da mesma forma, nossos achados parecem indicar que bilíngues engajam mais a rede fonológica que os monolíngues ao ler em sua L1. Esse resultado pode sugerir que ser bilíngue muda a forma como os indivíduos processam sua língua materna (BIALYSTOK et al., 2009).

Pode-se concluir que "a vantagem de ser bilíngue vem à custa de demandas crescentes de recuperação de palavras e articulação" (PARKER JONES et al., 2012, p.901, nossa tradução), mesmo numa atividade envolvendo a compreensão leitora de frases simples. De acordo com Bialystok e colegas (2009), o processamento da linguagem deve ser entendido como processos de recrutamento a partir do sistema cognitivo geral. À luz de tal observação, podemos perceber o recrutamento adicional de áreas pelos bilíngues que leem em sua língua materna como processos de gestão da atenção. Nas palavras de Bialystok (2011), "os circuitos de controle executivo necessários para gerenciar a atenção às duas línguas se integram aos circuitos linguísticos usados no processamento da linguagem, criando uma rede mais difusa, mais bilateral e mais eficiente que sustenta altos níveis de desempenho" (p.236, nossa tradução).

Assim, o presente estudo contribui para a literatura por ser o primeiro estudo com $\mathrm{fMRI} a$ estudar diretamente o processamento da linguagem nos cérebros de bilíngues do par linguístico português-inglês comparados aos cérebros de monolíngues do português.

O estudo aqui reportado parcialmente apenas foi possível graças a uma ação ascensional de internacionalização numa universidade federal brasileira, com fomento da CAPES. As autoras aproveitam a oportunidade para agradecer ao Dr. Marcel Just pela acolhida da primeira autora na Carnegie Mellon University no período 2014-2015, por todo o suporte do Center for Cognitive Brain Imaging. Sem o envolvimento da equipe interdisciplinar do 
laboratório, e o apoio da CAPES e da UFSC, este estudo não teria sido possível.

\section{Referências}

ABUTALEBI, Jubin; CAPPA, Stefano F.; PERANI, Daniela. (2001). The bilingual brain as revealed by functional neuroimaging. Bilingualism: Language and Cognition, v. 4, n. 2, p. 179-190, 2001.

AMARO JR., Edson; BARKER, Gareth J. Study design in fMRI: Basic principles. Brain and Cognition, v. 60, p. 220-232, 2006.

BAILER, Cyntia. Working memory capacity and attention to form and meaning in EFL reading. 2011. 181 f. Dissertação (Mestrado em Letras: Inglês e Literatura Correspondente) - Curso de Pós-Graduação em Inglês, Universidade Federal de Santa Catarina, Florianópolis, 29 nov 2011.

BAILER, Cyntia. The neural processing of sentences in bilinguals and monolinguals: an fMRI study of Portuguese-English bilinguals and Portuguese monolinguals reading comprehension effects on brain activation. 2016. $341 \mathrm{f}$. Tese (Doutorado em Estudos da Linguagem-Inglês) - Pós-Graduação em Inglês, Universidade Federal de Santa Catarina, Florianópolis.

BIALYSTOK, Ellen et al. Bilingual Minds. Psychological Science in the Public Interest, v. 10, n. 3, p. 89-129, 2009.

BIALYSTOK, Ellen. Reshaping the Mind: The Benefits of Bilingualism. Canadian Journal of Experimental Psychology, 65(4), p. 229-235, 2011.

BLEDOWSKI, Christoph, RAHM, Benjamin, \& ROWE, James B. (2009). What "Works" in Working Memory? Separate Systems for Selection and Updating of Critical Information. The Journal of Neuroscience, 29(43), p. 13735-13741, 2009.

BOHSALI, Anastacia A. et al. Broca's area - Thalamic connectivity. Brain \& Language, v. 141, p. 80-88, 2015.

BOLGER, Donald J., PERFETTI, Charles A., \& SCHNEIDER, Walter. Cross-Cultural Effect on the Brain Revisited: Universal Structures Plus Writing System Variation. Human Brain Mapping, v. 25, p. 92-104, 2005.

BUCHWEITZ, Augusto. Two languages, two input modalities, one brain: an fMRI study of Portuguese-English bilinguals and Portuguese listening and reading comprehension effects on brain activation. 2006. 194f. Tese (Doutorado em Língua Inglesa e Literatura Correspondente) Pós-graduação em Letras/Inglês e Literatura Correspondente, Universidade Federal de Santa Catarina, Florianópolis.
CABEZA, Roberto; NYBERG, Lars. Imaging cognition II: An empirical review of 275 PET and fMRI studies. Journal of Cognitive Neuroscience, v. 12, n. 1 , p. $1-47,2000$.

CAVANNA, Andrea E.; TRIMBLE, Michael R. The precuneus: a review of its functional anatomy and behavioural correlates. Brain, v. 129 , p. 564-583, 2006.

CRINION, J. et al. Language Control in Bilingual Brain. Science, v. 312, n. 9), p. 1537-1540, 2006.

DANEMAN, Meredyth; CARPENTER, Patricia A. Individual differences in working memory and reading. Journal of Verbal Learning and Verbal Behavior, v. 19, n. 4, p. 450-466, 1980.

DE SMET, Hyo J. et al. The cerebellum: Its role in language and related cognitive and affective functions. Brain \& Language, v. 127, p. 334-342, 2013.

DEHAENE, Stanislas. Reading in the brain. USA: Viking, 2009. $400 \mathrm{p}$.

DUFF, Melissa C.; BROWN-SCHMIDT, Sarah. The hippocampus and the flexible use and processing of language. Frontiers in human neuroscience, v. 6, p. 1-11, 2012.

GAGNÉ, ELLEN D.; YEKOVICH, Carol Walker; YEKOVICH, Frank R. The cognitive psychology of school learning. New York: Harper Collins College Publishers, 1993.

GROSJEAN, François. Studying bilinguals: Methodological and conceptual issues. Bilingualism: Language and Cognition, v. 1, p. 131-149, 1998.

ILLES, Judy et al. Convergent cortical representation of semantic processing in bilinguals. Brain and Language, 70, p. 347-363, 1999.

KELLER, Timothy; CARPENTER, Patricia; JUST, Marcel. The neural bases of sentence comprehension: An fMRI examination of syntactic and lexical processing. Cerebral Cortex, n. 11, p. 223-237, 2001.

KELLER, Timothy; CARPENTER, Patricia; JUST, Marcel. Brain imaging of tongue-twister sentence comprehension: Twisting the tongue and the brain. Brain and Language, v. 84, p. 189-203, 2003.

KIM, Karl H.S. et al. Distinct cortical areas associated with native and second languages. Nature, 388, p. 171-174, 1997.

KINTSCH, Walter; VAN DIJK, Teun A. Toward a Model of Text Comprehension and Production. Psychological Review, v. 85, n. 5, p. 363-394, 1978. 
KOVELMAN, Ioulia; BAKER, Stephanie A.; PETITTO, Laura-Ann. (2008). Bilingual and Monolingual Brains Compared: A Functional Magnetic Resonance Imaging Investigation of Syntactic Processing and a Possible "Neural Signature" of Bilingualism. Journal of Cognitive Neuroscience, v. 20, n. 1, p. 153-169, 2008.

MARIAN, Viorica, SPIVEY, Michael, \& HIRSCH, Joy. Shared and separate systems in bilingual language processing: Converging evidence from eyetracking and brain imaging. Brain and Language, 86, p. 70-82, 2003.

MASON, Robert A.; JUST, Marcel A. Physics instruction induces changes in neural knowledge representation during successive stages of learning. Neurolmage, v. 111, p. 36-48, 2015.

MECHELLI, Andrea et al. Differential effects of word length and visual contrast in the fusiform and lingual gyri during reading. Proc. $R$. Soc. Lond. $B$ 267, p. 1909-1913, 2000.

NEWMAN, Sharlene D. et al. Differential effects of syntactic and semantic processing on the subregions of Broca's area. Cognitive Brain Research, v. 16, p. 297-307, 2003.

PALOMAR-GARCÍA, María-Ángeles et al. Do bilinguals show neural differences with monolinguals when processing their native language? Brain \& Language, v. 142, p. 36-44, 2015.

PARKER JONES, Oiwi et al. Where, when and why brain activation differs for bilinguals and monolinguals during picture naming and reading aloud. Cerebral Cortex, v. 22, n. 4, p. 892-902, 2012.
Thomas J. Testing for Activation in Data from FMRI Experiments. Journal of Data Science, v. 4, p. 275-289, 2006.

$\mathrm{ROSCH}$, Eleanor et al. Basic objects in natural categories. Cognitive Psychology, v. 8, p. 382-439, 1976.

SCHWARTZ, Ana I.; KROLL, Judith F. Language Processing in Bilingual Speakers. In: TRAXLER, M.; GERNSBACHER, M. (Org.). Handbook of Psycholinguistics (2 ${ }^{\text {nd }}$ ed.). San Diego, CA, USA: Elsevier Academic Press, 2006, p. 967-999.

SHAYWITZ, Sally E.; SHAYWITZ, Bennett A. Dyslexia (Specific Reading Disability). Biological Psychiatry, v. 57, p. 1301-1309, 2005.

STOECKEL, Cornelia et al. Supramarginal gyrus involvement in visual word recognition. Cortex, v. 45, p. 1091-1096, 2009.

TOMITCH, Lêda M.B. (2003). Reading: text organization perception and working memory capacity. Florianópolis, SC: PGI/UFSC, ARES Advanced Research in English Series, 2003. 227 p.

TZOURIO-MAZOYER, Nathalie et al. Automated Anatomical Labeling of Activations in SPM Using a Macroscopic Anatomical Parcellation of the MNI MRI Single-Subject Brain. Neurolmage, v. 15, p. 273-289, 2002.

\section{COMO CITAR ESSE ARTIGO}

BAILER, Cyntia; TOMITCH, Lêda Maria Braga. Processamento neural de frases em português brasileiro em monolíngues e bilíngues: um estudo com fMRI dos efeitos da compreensão leitora na ativação cerebral. Signo, Santa Cruz do Sul, v. 44, n. 81, dez. 2019. ISSN 1982-2014. Disponível em: $<$ https://online.unisc.br/seer/index.php/signo/article/view/13723>. Acesso em: doi: https://doi.org/10.17058/signo.v44i81.13723.

PAVLICOVÁ, Martina; CRESSIE, Noel; SANTNER, 